point on 5 and that it was the most important and characteristic phenomenon in head injuries that the clinical condition of those scored above 6 , whose postoperative mortality were $87.5 \%$, resemble closely to the state of which had previously been described as brain stem syndrome.

One of the available signs to evaluate the state of severe head injuries is ECG changes, on which we have presented in the 13th Meeting of the Japan Society of Anesthesiology. The most remarkable electrocardiographic changes in severe head injuries was the depression of ST segment. It is significant that 45 out of 51 cases with depression of ST segment died postoperatively.

\title{
131. Diagnostic Value of Rest-N under Severe Head Injury
}

\author{
Masao Uyama, Satoshi Etani, Kiyomi Shigemoto, Kohichi Wakae \\ and Toshinori YANAGISAWA \\ Kyoto 2nd Red Cross Hospital, Energency Branch \\ Mitsuro Tohyama and Masayuki Funuma \\ Ist Department of Surgery, Kyoto Prefectural University of Medicine
}

Some biochemical examination; electrolite composition, protein metabolites, gass components of blood and etc. were measured in 60 cases of severe head injury. These components were varied by head injury, especially REST-N were abnormally increased, and azotemia in patients of severe head injury showed a specific finding.

In severe cases, the REST- $\mathrm{N}$ increased in early stage (after about $24 \mathrm{hrs}$.).

In the dead cases, the REST-N more increased rapidly over $100 \mathrm{mg} . / \mathrm{dl}$. after 72 hrs.

In survival cases, the REST-N was under $100 \mathrm{mg}$./dl. and the ratio in increase was small.

No changes was occurred in the urine volume and the urine specific gravity.

\section{Acid-base Balance Disorder in the Cases of Severe Acute Head Injury}

Tetsumi Mitani, Tohru Watanabe and Yuhzo Fujita

Department of Neurosurgery, Kokura Memorial Hospital 